\title{
The connection between non-communicable disease risk factors and risk perception among urban slum dwellers in Nairobi, Kenya
}

\author{
Tilahun Nigatu Haregu', Frederick Murunga Wekesah ${ }^{12}$, , Samuel Oti ${ }^{3}$, Thaddaeus Egondi ${ }^{4}$, and \\ Catherine Kyobutungi ${ }^{1}$ \\ ${ }^{1}$ African Population and Health Research Center, P.O. Box 10787 code 00100, Nairobi, Kenya \\ ${ }^{2}$ Julius Global Health, Julius Center for Health Sciences and Primary Care, Utrecht Medical Center, Huispost nr. \\ STR 6.131, P.O. Box 85500, 3508 GA Utrecht, the Netherlands. \\ ${ }^{3}$ International Development Research Centre PO Box 62084-00200, Nairobi, Kenya \\ ${ }^{4}$ Drugs for Neglected Diseases initiative (DNDi) Africa, P.O. Box 21936-00505, Nairobi, Kenya \\ tharegu@aphrc.org
}

\begin{abstract}
Non-communicable diseases (NCDs) are emerging as a public health issue in sub-Saharan Africa. This paper examines the relationship between the risk of NCDs and perceptions about such risk among urban slum population in Nairobi, Kenya. The analysis is based on data collected between 2008 and 2009 as part of a cross-sectional survey that was designed to assess linkages between socioeconomic status, perceived personal risk, and risk factors for cardiovascular and non-communicable diseases in urban slums of Nairobi. A total 5,190 study participants were included in the analysis. Low risk perception about NCDs in spite of the presence of NCD risk factors suggests the need for programmes aimed at creating awareness about the diseases and promoting the adoption of preventive healthy lifestyles among the urban poor populations of Nairobi.
\end{abstract}

Keywords: Non-communicable disease, risk factors, risk perception

\section{Résumé}

Les maladies non transmissibles (MNT) sont une menace émergente de santé publique en Afrique sub-saharienne. Cet article examine la relation entre le risque de maladies non transmissibles et les perceptions au sujet de tels risques dans une population d'habitants de bidonvilles à Nairobi, au Kenya. Cette analyse est basée sur les données recueillies dans le cadre d'une enquête transversale qui a été conçue pour évaluer les liens entre le statut socioéconomique, le risque personnel perçu, et les facteurs de risque de maladies cardio-vasculaires et non transmissibles dans une population de habitants des bidonvilles de Nairobi , au Kenya, en 2008-2009. Un total de 5190 participants à l'étude ont été inclus dans l'analyse. La principale conclusion est que les personnes vivant dans les bidonvilles ont une très faible perception du risque de contracter des maladies non transmissibles tandis que l'activité physique a été fortement associée à la perception du risque de contracter des maladies. Les résultats montrent que la faible perception du risque contribue à l'exposition aux facteurs de risque communs des maladies non transmissibles. Des interventions de changements de comportement qui influencent la perception de risque et de ce fait les facteurs de risques des MNT sont nécessaires.

Mots-clés: les maladies non transmissibles, facteurs de risque, la perception du risque

\section{Introduction}

The magnitude and burden of non-communicable diseases (NCDs) is rapidly increasing in the developing world (Wagner and Brath, 2012, Murray et al., 20/2). Along with the epidemiological, nutritional, demographic transitions, and environmental changes, rapid change in behavioural and lifestyle factors plays a significant role in the emergence of NCDs in many low and middle income countries. Among the known NCD risk factors, the four common behavioural risk factors (unhealthy diet, insufficient physical activity, harmful use of alcohol and tobacco use) contribute to the biggest share of NCD burden (Low et al., 2014, Martin-Diener et al., 2014). Analysis of trends of these common risk factors shows that their prevalence and the prevalence of their hazardous effects are consistently increasing in the developing world, including in sub- 
Saharan Africa (Ezzati and Riboli, 2013, Manjrekar et al., 2014, Sugathan et al., 2008).

NCD risk perception is central to behavioural change related to the prevention of these diseases (Brewer et al., 2007, Weinstein, 1993). It is crucial for the adoption of healthy lifestyles. Low level of perceived risk is usually associated with risky behaviours. Acknowledgement and understanding of NCD risk would lead to intentions towards healthy behaviours or less risky ones. Despite the importance of NCD risk perception in behaviour and lifestyle changes, studies have shown that underestimation of risk by individuals is very common. In this regard, it is essential to address people's misperception about their risk and/or underestimation of their risk level (Halpern-Felsher et al., 2004, Diaz et al., 2012, Morrison et al., 2010).

Appropriate level of risk perception is needed to change or limit NCD risk factors. However, in the analysis of risk perception of NCDs, much emphasis has been given to the relationship between perceived risk and clinical outcomes. A few studies have addressed the link between perceived and actual risk for NCDs (Hivert et al., 2009, Godino et al., 2014). Moreover, available studies on perceptions about NCD risk factors are limited to a single disease condition (Dabbak and Arafa, 2014). Other studies focused on the perceived need to change a single NCD risk factor or the levels of risk perception only (Vahasarja et al., 2012, Echouffo-Tcheugui and Kengne, 20II). The linkage between NCD risk perception and the common NCD risk factors (unhealthy diet, insufficient physical activity, harmful use of alcohol and smoking) has not received sufficient research attention especially in the context of low and middle income countries.

Therefore, this paper assess the association between the common NCD risk factors and NCD risk perception in a poor urban setting in Nairobi, Kenya. Available evidence indicates that the prevalence of hypertension and diabetes in this population is $12 \%$ and $5 \%$ respectively (van de Vijver et al., 2013, Oti et al., 20I3). Obesity was more prevalent among women (I5.5\%) than among men (2.3\%) (Ettarh et al., 20l4). The socio-economic status of the population is also low as informal work is the source of income for more than half of the study population and about two-thirds did not go beyond primary school. In this community, as it is also the case with other studies done elsewhere in Africa, the focus has been on identifying the prevalence and distribution of NCD risk factors among different segments of the population (Wandera et al., 2015, Kavishe et al., 2015, Kyari et al., 20I4, Helelo et al., 20I4, Moges et al., 20I4, Oladimeji et al., 2014, Kagaruki et al., 2014, Msyamboza et al., 20I4). As behavioural and lifestyle change starts from perceptions towards the risk, understanding the link between NCD risk factors and NCD risk perception is important for informing the design and implementation of behavioural interventions aimed at preventing and controlling NCDs.

\section{METHODS}

\section{Data source}

This paper draws on data from a large study that assessed the linkages between socio-economic status, perceived personal risk, and risk factors for cardiovascular and related NCDs. The study was implemented by the African Population and Health Research Center (APHRC) within the Nairobi Urban Health and Demographic Surveillance System (NUHDSS) population between May 2008 and April 2009. It used the sampling frame of the NUHDSS: a stratified sampling strategy based on the WHO STEPwise protocol with a target of 250 respondents in each of the following strata: sex, age group (I8-24, 25-30, 3I-40, 4I-50, 5I-60, and 60+), and slum of residence (Korogocho and Viwandani) for a total of 24 strata. Data were collected from a total of 5,190 individuals of age 18 years and above. Details of the sampling strategy, data collection methods, and data quality assurance mechanisms of the CVD study are published elsewhere (van de Vijver et al., 2013).

\section{Measurements}

NCD risk factors: The four common NCD risk factors (unhealthy diet, insufficient physical activity, harmful use of alcohol and tobacco use) were included in this analysis. Using standards for the definition of these risk factors (Table I), their presence or absence in an individual at the time of survey was ascertained using self-reported methods. 
Table I: Definition of the four NCD risk factors

\begin{tabular}{|c|c|c|}
\hline S\# & NCD risk factor & Definition used in this study \\
\hline I & Unhealthy diet & $\begin{array}{l}\text { Consumption of less than } 5 \text { portions of fruit and vegetables a day on at least five } \\
\text { days on an average week and/or greater than } 6 \text { teaspoon of sugar a day (World } \\
\text { Health Organization., 20l0b) }\end{array}$ \\
\hline 2 & $\begin{array}{l}\text { Insufficient } \\
\text { physical activity }\end{array}$ & $\begin{array}{l}\text { Less than } 75 \text { minutes of vigorous-intensity physical activity or Less than I50 } \\
\text { minutes of Moderate-intensity physical activity per week or equivalent of } \\
\text { combinations of these (from work, walking/cycling and leisure) (World Health } \\
\text { Organization., 2010a). }\end{array}$ \\
\hline 3 & $\begin{array}{l}\text { Harmful use of } \\
\text { alcohol (based on } \\
\text { daily consumption) }\end{array}$ & $\begin{array}{l}\text { More than } 3 \text { standard units/day for men; more than } 2 \text { standard units/day for } \\
\text { women (regardless of the type of alcohol consumed) (World Health } \\
\text { Organization., 2014) }\end{array}$ \\
\hline 4 & Tobacco use & $\begin{array}{l}\text { Current tobacco use as self-reported by the respondent (World Health } \\
\text { Organization., 2003) }\end{array}$ \\
\hline
\end{tabular}

NCD risk perception: The self-perceived risk to five major NCDs (Diabetes, hypertension, stroke, heart disease and heart attack) was measured in a fivepoint Likert scale (very high, high, moderate, low and very low). Those study participants with the disease were labelled as "already have the disease." These individuals were excluded from the analysis.

\section{Data analysis}

For the purpose of this analysis the risk perception scale was recoded in to a three-point scale (High, Moderate, and Low) for disease-specific risk perception and finally in to a dichotomous scale (Low and above low) for overall NCD risk perception. Summated scores were used to compute overall perceived risk to the five NCDs. Levels of perceived risk were used as predictor variables and presence of NCD risk factors were considered as outcome variables. Age categories of less than 45 years, 45-60 years and above 60 years were used. Proportions, mean and standard deviation were used to describe data; and tables and charts were used to present the findings. Chi-square statistics and logistic regression were used to assess the association between risk perception and risk factors. The regression models controlled for age and sex of the respondents. The results are presented as odds ratios (OR) with $95 \%$ confidence intervals.

Sampling probability weight was computed using the size of the stratum in the NUHDSS database as denominator and response probability was calculated using the total number sampled per stratum as denominator. A composite weight taking both sampling and response weights into account was applied to the main prevalence estimates.

\section{RESULTS}

NCD risk factors and NCD risk perception

Characteristics of the study population
Slightly less than half (46\%) of the study participants were females. Most of the participants $(56 \%)$ were aged between 18 and 45 years while $13 \%$ were more than 60 years old. More than half $(56 \%)$ were married at the time of the survey while $25 \%$ were widowed.

\section{Prevalence of NCD risk factors}

The weighted prevalence of unhealthy diet, insufficient physical activity, harmful use of alcohol and current smoking were $57.2 \%, 14.4 \%, 10.1 \%$ and $12.4 \%$, respectively. Unhealthy diet and insufficient physical activity were more prevalent among women than men while use of alcohol and smoking were more prevalent among men than women.

\section{NCD risk perception}

The majority of the study population had low level of risk perception for the five NCDs considered in this analysis. For each of the five NCDs, at least threefourth of the study participants felt that their chance of getting the specific NCD is low (Table 2). Those who felt that they have moderate level of risk ranges between $10 \%$ and $20 \%$. The mean (SD) perceived risk score for the five diseases was 5.85 (I.52). In the overall categorized risk score, $87.6 \%$ had low perceived risk and $12.4 \%$ had high perceived risk for NCDs. Nearly two-third (64.2\%) of the study population had low perceived risk for all the five NCDs combined (not shown). 
Table 2: Levels of NCD Risk perception

\begin{tabular}{rlccll}
\hline SN & Type of NCD & High (=3) & Moderate (=2) & Low (=I) & “I don't know” \\
\hline I & Diabetes & I $44(3.5 \%)$ & $716(17.3 \%)$ & $3,278(79.2 \%)$ & $958(18.5 \%)$ \\
2 & Hypertension & $275(6.8 \%)$ & $817(20.0 \%)$ & $2,984(73.2 \%)$ & $867(16.7 \%)$ \\
$\mathbf{3}$ & Stroke & $63(1.6 \%)$ & $394(10.1 \%)$ & $3,443(88.3 \%)$ & $1,279(24.7 \%)$ \\
$\mathbf{4}$ & Heart disease & $123(3.0 \%)$ & $632(15.3 \%)$ & $3,379(81.7 \%)$ & $1,040(20.0 \%)$ \\
$\mathbf{5}$ & Heart attack & $83(2.3 \%)$ & $356(9.8 \%)$ & 3,200 & $1,542(29.7 \%)$ \\
& & & & $(87.9 \%)$ & \\
\hline
\end{tabular}

There were statistically significant variations in the levels of perceived risk of NCDs by sex. In particular, levels of perceived risk of NCDs were significantly higher among women than men. Similarly, the mean considered in the analysis was significantly higher among women than men (5.95 and 5.78 respectively; $p=0.000$ ). The distribution of NCD risk perception by sex is shown in Figure I.

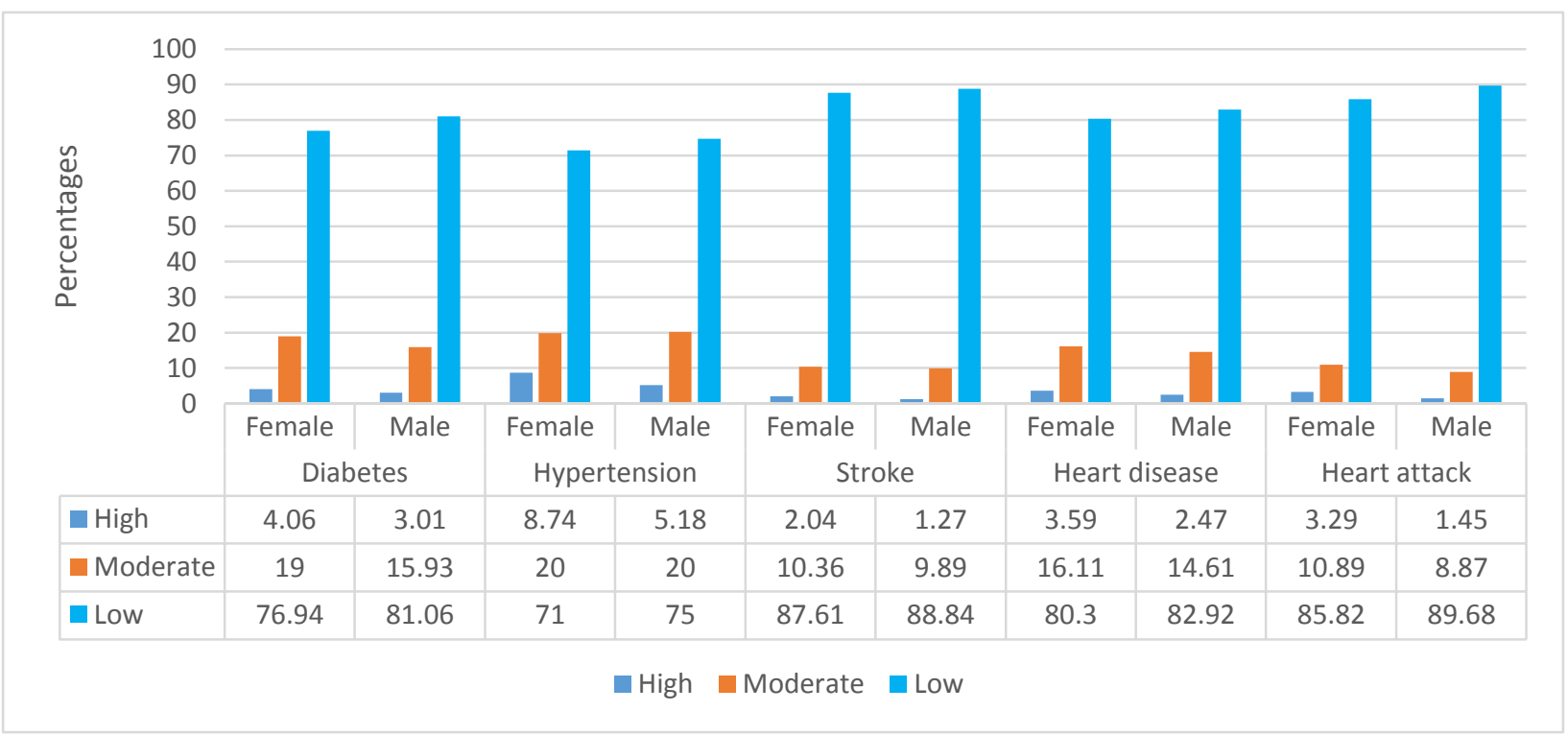

Fig I. NCD risk perception by sex

Analysis of NCD risk perception by age also shows that there is no substantial increment in levels of perceived risk as age increases despite the fact that the actual risk of getting NCDs increases with age. However, there is some level of increase in perceived risk between those less than 45 years and those 45 60 years.
Likewise, the mean (SD) of the summated perceived risk score for those aged below 45 years, 45-60 years, and above 60 years were $5.83(I .5 \mathrm{I})$, $5.89(1.55)$ and 5.87(I.53), respectively. However, there was no statistically significant difference in the mean of summated perceived risk scores across these age categories. The levels of perceived risk for the different NCDs are shown in Figure 2. 


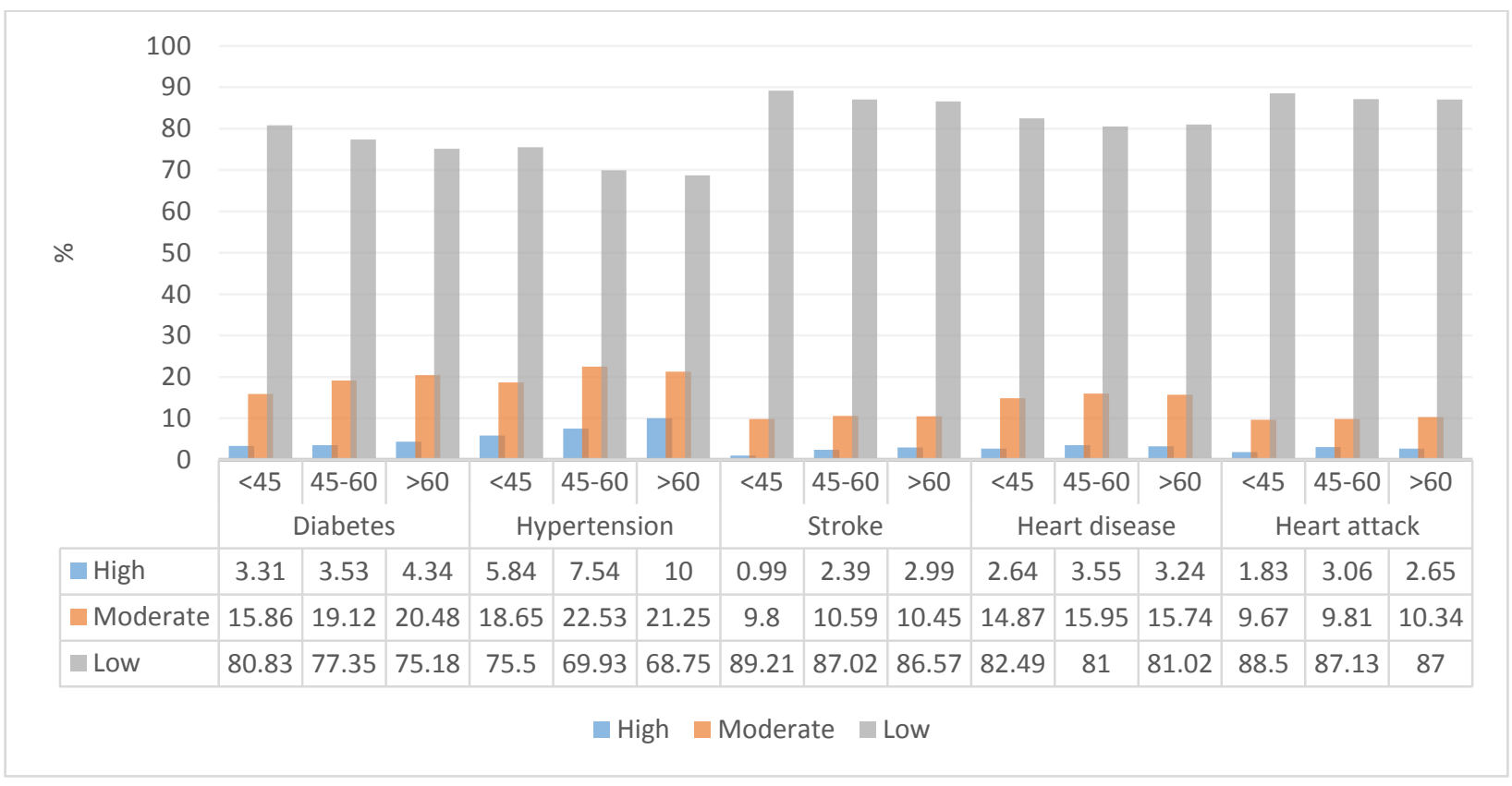

Fig 2. Levels of perceived NCD risk by age categories

Association between NCD risk perception and risk factors NCD risk perception and risk factors for specific diseases Results from analysis of the association between perceived risk of diabetes and its risk factors showed that those with moderate perceived risk were significantly more likely to have unhealthy dietary behaviour $(O R=1.18 ; 95 \% \mathrm{Cl}$ : I.0I, I.40) than those with low perceived risk (Table 3). By contrast, having moderate perceived risk of the disease was associated with significantly lower likelihood of engaging in insufficient physical activity compared with having low perceived risk $(\mathrm{OR}=0.63$; 95\% Cl: 0.49, 0.8I).

With respect to hypertension, the results showed that those with moderate levels of perceived risk were significantly more likely to have unhealthy diet $(\mathrm{OR}=1.3 \mathrm{I} ; 95 \% \mathrm{Cl}: \mathrm{I} . \mathrm{II}, \mathrm{I} .54)$ but significantly less likely to be engaged in insufficient physical activity $(\mathrm{OR}=0.55 ; 95 \% \mathrm{Cl}: 0.44,0.7 \mathrm{l})$ compared with those having low perceived risk. The results for stroke, on the other hand, showed that those with moderate perceived risk were significantly less likely to be engaged in insufficient physical activity compared with those with low perceived risk $(\mathrm{OR}=0.55 ; 95 \% \mathrm{Cl}$ : $0.39,0.78$ ).

The results examining the association between perceived risk of heart disease and its risk factors showed that those with moderate or high perceived risk were significantly less likely to be engaged in insufficient physical activity compared with those having low perceived risk $(\mathrm{OR}=0.53 ; 95 \% \mathrm{Cl}: 0.40$, $0.69 ;$ and $\mathrm{OR}=0.35 ; 95 \% \mathrm{Cl}: 0.18, \quad 0.68$ respectively). In addition, those with moderate perceived risk were significantly less likely to be engaged in harmful use of alcohol compared with those having low perceived risk $(\mathrm{OR}=0.68 ; 95 \% \mathrm{Cl}$ : $0.48,0.98)$. The results for heart attack, on the other hand, showed that those with moderate risk perception were significantly more likely to report insufficient physical activity compared with those having low perceived risk $(\mathrm{OR}=1.55 ; 95 \% \mathrm{Cl}: 1.10$, 2.21 )

Table 3: Association between dichotomous categories of risk perception and risk factors

\begin{tabular}{|c|c|c|c|c|}
\hline & Unhealthy diet & $\begin{array}{l}\text { Insufficient } \\
\text { physical activity }\end{array}$ & $\begin{array}{l}\text { Harmful use of } \\
\text { alcohol }\end{array}$ & Current smoking \\
\hline Diabetes & $1.22[1.05,1.43]$ & $0.67[0.54,0.84]$ & $0.88[0.66,|| 8]$. & $0.85[0.66, I . I I]$ \\
\hline Hypertension & $1.26[1.09,1.46]$ & $0.61[0.49,0.76]$ & I.I5[0.89,।.49] & $1.03[0.82,1.29]$ \\
\hline Stroke & $\mathrm{I} .05[0.86, \mathrm{I} .28]$ & $0.60[0.45,0.82]$ & $0.72[0.48,1.08]$ & $1.06[0.77, \mathrm{I} .46]$ \\
\hline Heart disease & $1.38[1.17,1.63]$ & $0.49[0.38,0.64]$ & $0.66[0.47,0.92]$ & $\mathrm{I} .05[0.8 \mathrm{I}, \mathrm{I} .37]$ \\
\hline Heart attack & $1.16[0.94,1.42]$ & $0.69[0.52,0.93]$ & I. $14[0.79,1.64]$ & $1.49[1.10,2.04]$ \\
\hline All NCDs & $1.2 \mid[0.97, \mid .5 \mathrm{I}]$ & $0.69[0.51,0.95]$ & $0.95[0.63,1.43]$ & $1.08[0.76, \mid .55]$ \\
\hline
\end{tabular}

Note: All associations are adjusted for age and sex 
NCD risk factors and Overall NCD risk perception

There were no statistically significant differences in the proportions of respondents that had moderate or high overall risk perception of NCDs among those with and without unhealthy diet (11\% and $14 \%$ respectively; $\mathrm{OR}=1.2 \mathrm{I} ; 95 \% \mathrm{Cl}: 0.97, \mathrm{I} .5 \mathrm{I})$, harmful use of alcohol $(13 \%$ and $11 \%$ respectively; $\mathrm{OR}=0.95 ; 95 \% \mathrm{Cl}: 0.63, \quad \mathrm{l} .43$ ) or smoking behaviours ( $13 \%$ and $11 \%$ respectively; $O R=I .08$; $95 \% \mathrm{Cl}: 0.75$, I.55). However, the proportion having moderate or high overall perceived risk was significantly lower among those reporting than among those who did not report insufficient physical activity $(10 \%$ and $13 \%$ respectively; OR $=0.70 ; 95 \% \mathrm{Cl}$ : $0.5 \mathrm{I}, 0.95)$ (Table 4).

Table 4: Overall NCD risk perception and NCD risk factors

\begin{tabular}{|c|c|c|c|c|c|}
\hline \multirow{2}{*}{\multicolumn{2}{|c|}{ NCD risk factors }} & \multicolumn{4}{|c|}{ Overall Perceived NCD risk } \\
\hline & & Low & Above low & Total & OR $(95 \% \mathrm{Cl})$ \\
\hline Unhealthy & No & I,308(88.9\%) & $162(11.0 \%)$ & I,470 & $\mathrm{I} .2 \mathrm{I}[0.97, \mathrm{I} .5 \mathrm{I}]$ \\
\hline diet & Yes & $1,444(86.4 \%)$ & $227(\mid 3.6 \%)$ & $|, 67|$ & \\
\hline Insufficient & No & $2,287(87.2 \%)$ & $335(\mid 2.8 \%)$ & 2,622 & $0.70[0.51,0.95]$ \\
\hline $\begin{array}{l}\text { physical } \\
\text { activity }\end{array}$ & Yes & $465(89.6 \%)$ & $54(10.4 \%)$ & 519 & \\
\hline Harmful use & No & $2,500(87.4 \%)$ & $359(\mid 2.6 \%)$ & 2,859 & $0.95[0.63,1.43]$ \\
\hline of alcohol & Yes & $252(89.4 \%)$ & $30(10.6 \%)$ & 282 & \\
\hline Current & No & $2,4 \mid 7(87.5 \%)$ & $346(\mid 2.5 \%)$ & 2,763 & $\mathrm{I} .08[0.75,1.55]$ \\
\hline smoking & Yes & $335(88.6 \%)$ & $43(\mid 1.4 \%)$ & 378 & \\
\hline
\end{tabular}

NCD risk perception and co-occurrence of NCD risk factors

The majority (88\%) of the respondents who did not have any of the four NCD risk factors had low risk perception about the diseases. Although those with moderate or high risk perception were more likely to have at least one NCD risk factor compared with those having low risk perception, the difference was not statistically significant $(\mathrm{OR}=1.08 ; 95 \% \mathrm{Cl}: 0.85$, I.36). Similar to those having no risk factors, the majority $(89 \%)$ of respondents with multiple NCD risk factors had low risk perception about the diseases ( $86 \%$ of females and $90 \%$ of males). There was no statistically significant association between risk perception and having multiple NCD risk factors $(\mathrm{OR}=0.89 ; 95 \% \mathrm{Cl}: 0.68, \mathrm{I} .18)$.

\section{Discussion}

The main findings of this study show that the majority of the urban poor adults have relatively low prevalence of the three key NCD risk factors (insufficient physical activity, harmful use of alcohol and smoking). However, the prevalence of unhealthy diet was high. The majority of the study participants perceived that they had low risk of getting each of the five NCDs that are considered in this analysis (Diabetes, Hypertension, Stroke, Heart disease and heart attack). Even among those with multiple NCD risk factors, only $12 \%$ had above low risk perception.

The findings showed that unhealthy diet and tobacco use were not significantly associated with NCD risk perception. However, those with moderate or high risk perception were significantly less likely to be engaged in insufficient physical activity or harmful use of alcohol. In addition, there was no significant difference in risk perception between those with and those without multiple risk factors. The findings imply that knowledge about NCDs and their risk factors is generally low among the urban slum populations of Nairobi. Studies show that underestimation of risk among high risk individuals is common and may lead to a situation where those reporting lower risks for NCDs are less likely to seek treatment and adopt healthy and preventive lifestyles (Petr et al., 20I4, Everett et al., 20I4).

A study conducted in Croatia showed that there was no difference in the perceptions of risk among older adults who had the actual risk factors present compared to those older adults without the risk factors (Mazalin Protulipac et al., 2015). A study in the United States showed that despite the potential high risk of developing diabetes among the African American living in urban settings, their perception for risk was low (Calvin et al., 20l I). The findings of this paper regarding the lack of significant association between NCD risk factors and perceived risk of the diseases are consistent with existing evidence.

The low perception of NCD risk among this urban poor population could be attributed to lack of awareness, and low education levels in the community as has been demonstrated elsewhere (Miranda et al., 2008). Studies show that there are variations in the prevalence of NCD risk factors in low- and middle-income countries with those from the poorest households bearing the heaviest burden (Hosseinpoor et al., 2012, Marins et al., 2007). The evidence suggests the need for creating awareness 
about NCDs and designing evidence-informed interventions to reduce the risk factors associated with the diseases among urban poor populations.

The findings of this paper have important implications for policy and practice. For appropriate behavioural and lifestyle modification, people with NCD risk factors need to have an appropriate level of risk perception (i.e. a risk perception that concurs with actual risk) where those with heightened risks for NCDs due to behavioural and physiological risk factors take deliberate decisions to adopt health lifestyles and behaviour modification. However, this study has revealed that most of those having NCD risk factors had low risk perception. Low risk perception in the context of growing NCD epidemic is likely to affect efforts aimed at creating awareness about and improving the uptake of preventive and healthy lifestyles, especially among the urban poor (Katz et al., 20I4).

Understanding how individuals estimate and assess their own risk factors for NCDs is also useful for designing targeted interventions aimed at improving risk communication and health outcomes among the urban poor (Renner et al., 2008). In particular, behavioural interventions should aim at creating awareness about NCDs and promoting the adoption of healthy lifestyles among those at high risk. Based on the findings, such interventions should mainly focus on unhealthy diet and tobacco use as individuals with these risk factors had low risk perception about contracting NCDs.

The findings of the paper may be influenced by certain limitations. In particular, given the crosssectional nature of the study that provided the data for the paper, it is not possible to determine cause and effect regarding the relationship between NCD risk factors and risk perception. . As change in perception can result in change in behaviour and vice versa, antecedent-consequence uncertainty is a major limitation due to fact that temporal sequence could not be established. In addition, the measurement of both risk perception and risk factors for NCDs was self-reported and could be subject to bias, mostly towards underestimation of risk.

In conclusion, low risk perception about NCDs in spite of the presence of NCD risk factors suggests the need for programmes aimed at creating awareness about the diseases and promoting the adoption of preventive healthy lifestyles among the urban poor populations of Nairobi.

\section{Acknowledgement}

The study was part of a larger research project supported by a grant from the Welcome Trust UK (grant no. WT092775MA). We also acknowledge all the study participants and all members of the research team who conducted the study.

\section{Authors' Contribution}

$\mathrm{TNH}$ and FW conceptualized the study, drafted the plan of analysis, conducted the analysis and drafted the manuscript. SO, TE, and CK provided substantial inputs in the design of the study, plan of analysis and the draft manuscript. They were also among the core team members in the main cardiovascular disease study.

\section{Ethics Statement}

Approval to conduct the study was sought from and granted by the Kenya Medical Research Institute's Ethical Review Committee (NON-SSC Protocol No.339). Participants provided written consent following full disclosure regarding the study objectives before data collection.

\section{Conflict of Interest}

The authors declare that they have no conflict of interests associated with this study.

\section{References}

BREWER, N. T., CHAPMAN, G. B., GIBBONS, F. X., GERRARD, M., MCCAUL, K. D. \& WEINSTEIN, N. D. 2007. Meta-analysis of the relationship between risk perception and health behavior: the example of vaccination. Health Psychology, 26, 136.

CALVIN, D., QUINN, L., DANCY, B., PARK, C., FLEMING, S. G., SMITH, E. \& FOGELFELD, L. 20II. African Americans' perception of risk for diabetes complications. Diabetes Educ, 37, 68998.

DABBAK, H. \& ARAFA, M. A. 20I4. Risk Assessment and Risk Perception of Coronary Heart Disease in Gaza Strip, Palastine. Health, Vol.06No.2I, II.

DIAZ, V. A., MAINOUS, A. G., 3RD, WILLIAMSON, D., JOHNSON, S. P. \& KNOLL, M. E. 2012. Cardiovascular and diabetes risk perception in a Hispanic community sample. Ethn Dis, 22, 5-II.

ECHOUFFO-TCHEUGUI, J. B. \& KENGNE, A. P. 2011. Chronic non-communicable diseases in Cameroon - burden, determinants and current policies. Global Health, 7, 44.

ETTARH, R., VAN DE VIJVER, S., OTI, S. \& KYOBUTUNGI, C. 20I4. Overweight, Obesity, and Perception of Body Image Among Slum Residents in Nairobi, Kenya, 2008-2009. Preventing Chronic Disease, II, E2I 2.

EVERETT, B., SALAMONSON, Y., ROLLEY, J. X. \& DAVIDSON, P. M. 20I4. Underestimation of risk 
perception in patients at risk of heart disease. Eur J Cardiovasc Nurs.

EZZATI, M. \& RIBOLI, E. 20I3. Behavioral and Dietary Risk Factors for Noncommunicable Diseases. New England Journal of Medicine, 369, 954-964.

GODINO, J. G., VAN SLUIJS, E. M., SUTTON, S. \& GRIFFIN, S. J. 20I4. Understanding perceived risk of type 2 diabetes in healthy middle-aged adults: a cross-sectional study of associations with modelled risk, clinical risk factors, and psychological factors. Diabetes Res Clin Pract, I06, 4I 2-9.

HALPERN-FELSHER, B. L., BIEHL, M., KROPP, R. Y. \& RUBINSTEIN, M. L. 2004. Perceived risks and benefits of smoking: differences among adolescents with different smoking experiences and intentions. Prev Med, 39, 559-67.

HELELO, T. P., GELAW, Y. A. \& ADANE, A. A. 2014. Prevalence and associated factors of hypertension among adults in Durame Town, Southern Ethiopia. PLoS One, 9, el I 2790.

HIVERT, M. F., WARNER, A. S., SHRADER, P., GRANT, R. W. \& MEIGS, J. B. 2009. Diabetes Risk Perception and Intention to Adopt Healthy Lifest yles Among Primary Care Patients. Diabetes Care, 32, 1820-2.

HOSSEINPOOR, A., BERGEN, N., KUNST, A., HARPER, S., GUTHOLD, R., REKVE, D., D'ESPAIGNET, E., NAIDOO, N. \& CHATTERJI, S. 20I2. Socioeconomic inequalities in risk factors for non communicable diseases in low-income and middle-income countries: results from the World Health Survey. BMC Public Health, 12, 91 2.

KAGARUKI, G. B., MAYIGE, M. T., NGADAYA, E. S., KIMARO, G. D., KALINGA, A. K., KILALE, A. M., KAHWA, A. M., MATERU, G. S. \& MFINANGA, S. G. 2014. Magnitude and risk factors of noncommunicable diseases among people living with HIV in Tanzania: a cross sectional study from Mbeya and Dar es Salaam regions. BMC Public Health, 14, 904.

KATZ, M., LAURINAVICIUS, A. G., FRANCO, F. G., CONCEICAO, R. D., CARVALHO, J. A., PESARO, A. E., WAJNGARTEN, M. \& SANTOS, R. D. 20I4. Calculated and perceived cardiovascular risk in asymptomatic subjects submitted to a routine medical evaluation: The perception gap*. Eur J Prev Cardiol.

KAVISHE, B., BIRARO, S., BAISLEY, K., VANOBBERGHEN, F., KAPIGA, S., MUNDERI, P., SMEETH, L., PECK, R., MGHAMBA, J., MUTUNGI, G., IKOONA, E., LEVIN, J., BOU MONCLUS, M. A., KATENDE, D., KISANGA, E., HAYES, R. \& GROSSKURTH, H. 2015. High prevalence of hypertension and of risk factors for non-communicable diseases (NCDs): a population based cross-sectional survey of NCDS and HIV infection in Northwestern Tanzania and Southern Uganda. BMC Med, I3, 126.

KYARI, F., TAFIDA, A., SIVASUBRAMANIAM, S., MURTHY, G. V., PETO, T. \& GILBERT, C. E. 20I4. Prevalence and risk factors for diabetes and diabetic retinopathy: results from the Nigeria national blindness and visual impairment survey. BMC Public Health, 14, 1299.

LOW, W. Y., LEE, Y. K. \& SAMY, A. L. 20I4. Noncommunicable diseases in the Asia-Pacific region: Prevalence, risk factors and community-based prevention. Int J Occup Med Environ Health.

MANJREKAR, S. S., SHERKHANE, M. S. \& CHOWTI, J. V. 20I4. Behavioral risk factors for noncommunicable diseases in working and nonworking women of urban slums. J Midlife Health, 5, I43-9.

MARINS, V., ALMEIDA, R., PEREIRA, R. \& SICHIERI, R. 2007. The association between socioeconomic indicators and cardiovascular disease risk factors in Rio de Janeiro, Brazil. J Biosoc Sci, 39, 221 229.

MARTIN-DIENER, E., MEYER, J., BRAUN, J., TARNUTZER, S., FAEH, D., ROHRMANN, S. \& MARTIN, B. W. 20I4. The combined effect on survival of four main behavioural risk factors for non-communicable diseases. Prev Med, 65, I4852.

MAZALIN PROTULIPAC, J., SONICKI, Z. \& REINER, Z. 20I5. Cardiovascular disease (CVD) risk factors in older adults - Perception and reality. Arch Gerontol Geriatr, 61, 88-92.

MIRANDA, J., KINRA, S., CASAS, J., DAVEY, S. \& EBRAHIM, S. 2008. Non-communicable diseases in low- and middle-income countries: context, determinants and health policy. Trop Med Int Health, 13, 1225 - 1234.

MOGES, B., AMARE, B., FANTAHUN, B. \& KASSU, A. 20I4. High prevalence of overweight, obesity, and hypertension with increased risk to cardiovascular disorders among adults in northwest Ethiopia: a cross sectional study. BMC Cardiovasc Disord, I4, I55.

MORRISON, M. K., LOWE, J. M. \& COLLINS, C. E. 2010. Perceived risk of Type 2 diabetes in Australian women with a recent history of gestational diabetes mellitus. Diabet Med, 27, 882-6.

MSYAMBOZA, K. P., MVULA, C. J. \& KATHYOLA, D. 20I4. Prevalence and correlates of diabetes mellitus in Malawi: population-based national NCD STEPS survey. BMC Endocr Disord, I4, 4I.

MURRAY, C., VOS, T., LOZANO, R., NAGHAVI, M. \& FLAXMAN, A. 2012. Global burden of diseases 
and injuries for 29I causes and 21 regions. 19902012: a systematic analysis for the Global Burden of Disease Study 20 I0. Lancet, 380, 21 97-2223.

OLADIMEJI, A. M., FAWOLE, O., NGUKU, P. \& NSUBUGA, P. 20/4. Prevalence and factors associated with hypertension and obesity among civil servants in Kaduna, Kaduna State, June 2012. Pan Afr Med J, I 8 Suppl I, I 3.

OTI, S. O., VAN DE VIJVER, S. J., AGYEMANG, C. \& KYOBUTUNGI, C. 20I3. The magnitude of diabetes and its association with obesity in the slums of Nairobi, Kenya: results from a crosssectional survey. Trop Med Int Health, 18, 152030.

PETR, E. J., AYERS, C. R., PANDEY, A., DE LEMOS, J. A., POWELL-WILEY, T. M., KHERA, A., LLOYD-JONES, D. M. \& BERRY, J. D. 2014. Perceived lifetime risk for cardiovascular disease (from the Dallas Heart Study). Am J Cardiol, I I4, 53-8.

RENNER, B., SCHUPP, H., VOLLMANN, M., HARTUNG, F.-M., SCHMÄLZLE, R. \& PANZER, M. 2008. Risk perception, risk communication and health behavior change: Health psychology at the University of Konstanz. Zeitschrift für Gesundheitspsychologie, 16, I50-153.

SUGATHAN, T. N., SOMAN, C. R. \& SANKARANARAYANAN, K. 2008. Behavioural risk factors for non communicable diseases among adults in Kerala, India. Indian J Med Res, I27, 55563.

VAHASARJA, K., SALMELA, S., VILLBERG, J., RINTALA, P., VANHALA, M., SAARISTO, T., PELTONEN, M., KEINANEN-KIUKAANNIEMI, S., KORPI-HYOVALTI, E., KUJALA, U. M.,
MOILANEN, L., NISKANEN, L., OKSA, H. \& POSKIPARTA, M. 20I2. Perceived need to increase physical activity levels among adults at high risk of type 2 diabetes: a cross-sectional analysis within a community-based diabetes prevention project FIN-D2D. BMC Public Health, I2, 514 .

VAN DE VIJVER, S. J., OTI, S. O., AGYEMANG, C., GOMEZ, G. B. \& KYOBUTUNGI, C. 2013. Prevalence, awareness, treatment and control of hypertension among slum dwellers in Nairobi, Kenya. J Hypertens, 31, I0I8-24.

WAGNER, K. H. \& BRATH, H. 20I2. A global view on the development of non communicable diseases. Prev Med, 54 Suppl, S38-4I.

WANDERA, S. O., KWAGALA, B. \& NTOZI, J. 2015. Prevalence and risk factors for self-reported noncommunicable diseases among older Ugandans: a cross-sectional study. Glob Health Action, 8, 27923.

WEINSTEIN, N. D. 1993. Testing four competing theories of health-protective behavior. Health psychology, 12, 324.

WORLD HEALTH ORGANIZATION. 2003. WHO Framework Convention on Tobacco Control.

WORLD HEALTH ORGANIZATION. 20I0a. Global recommendations on physical activity for health. Geneva, Switzerland: WHO Press.

WORLD HEALTH ORGANIZATION. 20I0b. Healthy Diet [Online]. Available: http://www.who.int/mediacentre/factsheets/fs394 len/ [Accessed Jan 25 20I5].

WORLD HEALTH ORGANIZATION. 20I4. Global status report on alcohol and health Luxembourg: World Health Organization. 